\title{
Erratum to: Photography as a Social Research Method
}

\section{Erratum to:}

\section{S. Langmann and D. Pick, Photography as a Social Research Method, https://doi.org/10.1007/978-981-10-7279-6}

In the original version of the book, the following corrections have been incorporated:

In Chaps. 2 and 6, placement of figures have been changed.

In Chap. 5, corrections from the author have been incorporated.

The erratum book has been updated with the changes.

The updated online version of these chapters can be found at https://doi.org/10.1007/978-981-10-7279-6_2

https://doi.org/10.1007/978-981-10-7279-6_5

https://doi.org/10.1007/978-981-10-7279-6_6 